\title{
INCREASING EFFICIENCY OF THE PYROLYSIS PROCESS BY INFLUENCING THE INITIATION OF THERMAL DECOMPOSITION OF HYDROCARBONS
}

\author{
ELENA MAGARIL ${ }^{1} \&$ ROMEN MAGARIL ${ }^{2}$ \\ ${ }^{1}$ Ural Federal University, Russian Federation \\ ${ }^{2}$ Tyumen Industrial University, Russian Federation
}

\begin{abstract}
Mono-olefins produced in the process of pyrolysis of the hydrocarbon feedstock are one of the main sources for petrochemical synthesis, that accounts for the importance of searching for methods to improve the process. The aim of the work is to develop a method for increasing efficiency of the pyrolysis process on the basis of the allene effect on thermal decomposition of hydrocarbons, which are the pyrolysis feedstock constituents and also form in the process. Effect of the allene addition on thermal decomposition of hexene-1, hexane and gasoline fraction of oil was studied. It was shown that in the presence of allene the rate of thermal decomposition of hydrocarbons significantly increases. Carrying out the pyrolysis process in the presence of allene additionves allows one to lower the temperature of the process at a given time or the reaction time at a given temperature.

Keywords: pyrolysis, allene, radical chain reaction, chain initiation stage.
\end{abstract}

\section{INTRODUCTION}

Industry of organic synthesis is based mainly on the hydrocarbon feedstock, during the pyrolysis of which various hydrocarbons are produced, particularly ethylene, which serves as a base for manufacturing a significant part of petrochemical products. Ethan, propane and butane contained in the associated gases of oil production, natural gas gasoline and low-octane gasolines obtained by direct distillation of oil are used as the pyrolysis feedstock to produce ethylene. In countries with insufficient reserves of gaseous and light liquid hydrocarbons, any petroleum fractions are used as raw materials for the pyrolysis to obtain ethylene. It is projected that by 2020 the world production of ethylene will total 200 million tons per year [1]. Continuous growth of the global demand for ethylene necessitates the development of more effective pyrolysis methods, which allow increasing the yield of the target products [2].

The influence over the chain initiation stage using the knowledge on the radical chain mechanism of thermal reactions of hydrocarbons is one of the means to force the pyrolysis process. It is of considerable practical interest to accelerate the thermal decomposition of hydrocarbons using highly effective initiating additives. According to [3], bimolecular chain initiating reactions will matter in the pyrolysis process only if they have the activation energy of at least $170 \mathrm{~kJ}$ less than that for a competing first-order initiating reaction. Reactions of hydrocarbons with allene meet this condition. At present, there is an increasing interest in the pyrolysis of biomass [4]-[6], for which the study of acceleration of chain initiation using allene also may be of interest.

\section{EFFECT OF THE CHAIN INITIATION STAGE ON THE KINETICS OF THERMAL DECOMPOSITION OF HYDROCARBONS}

The process of thermal decomposition of hydrocarbons proceeds at a constant rate with the equal rates of formation and destruction of radicals, while the concentration of radicals $[\dot{R}]$ 
is constant and determined from the equality (1) of the rates of the chain initiation and chain termination:

$$
v=k_{0} \cdot[\dot{R}]^{2}
$$

where $v$ is the rate of the chain initiation, $k_{0}$ is the rate constant of chain termination.

Thus, the rate of the reaction can be determined from the eqn (2):

$$
V=k \cdot \sqrt{\frac{v}{k_{0}}} \cdot[M]
$$

where $[\mathrm{M}]$ is the concentration of molecules; the reaction rate is proportional to the rate of chain initiation to the power $\frac{1}{2}$.

Let us consider the thermolysis of n-hexane. The initial formation of the radicals proceeds according to the reaction (3):

$$
\mathrm{C}_{6} \mathrm{H}_{14}=2 \dot{\mathrm{C}}_{3} \mathrm{H}_{7}-343 \mathrm{~kJ} / \mathrm{mol}
$$

(thermodynamic data given in [7], were used to calculate the thermal effect of the reaction). As a result of the chain decomposition reaction of n-hexane, n-pentene- 1 is formed. Its decomposition by the reaction (4):

$$
\mathrm{CH}_{2}=\mathrm{CH}-\mathrm{CH}_{2}-\mathrm{CH}_{2}-\mathrm{CH}_{3} \rightarrow \dot{\mathrm{C}}_{3} \mathrm{H}_{5}+\dot{\mathrm{C}}_{2} \mathrm{H}_{5}-292 \mathrm{~kJ} / \mathrm{mol}
$$

requires an energy expenditure of $51 \mathrm{~kJ} / \mathrm{mol}$ less than that by the reaction (3) (thermodynamic data given in $[7,8]$ were used for the calculation).

Estimation of the rate of the reactions of decomposition of n-pentene-1 (4) and decomposition of n-hexane (3) shows that at the equal pre-exponents the decomposition of n-pentene- 1 occurs at $800 \mathrm{~K}$ faster than that of hexane by a factor of $\frac{e^{-\frac{292000}{R \cdot 800}}}{e^{-\frac{342000}{R \cdot 800}}}=10^{3.3}$, i.e.

even at a very small degree of n-hexane decomposition, the chains are initiated on npentene-1, which is the product of decomposition. Thus, the initiation of the chains by the decomposition of $\mathrm{n}$-hexane does not matter.

Even if we assume that the pre-exponent of the n-pentene-1 decomposition is by an order of magnitude smaller than the pre-exponent factor of the n-hexane decomposition, the initiation of the chains will still be determined by the decomposition of n-pentene-1.

The authors have experimentally established that the thermal decomposition of isobutene is self-accelerated, and suggested that this self-acceleration is associated with the course of the reactions (5) and (6):

$$
\begin{aligned}
& \mathrm{CH}_{2}=\mathrm{C}\left(\mathrm{CH}_{3}\right)_{2}+\dot{\mathrm{C}} \mathrm{H}_{3} \rightarrow \mathrm{CH}_{2}=\mathrm{C}\left(\mathrm{CH}_{3}\right) \dot{\mathrm{C}} \mathrm{H}_{2}+\mathrm{CH}_{4} \\
& \mathrm{CH}_{2}=\mathrm{C}\left(\mathrm{CH}_{3}\right) \dot{C} \mathrm{H}_{2} \rightarrow \mathrm{CH}_{2}=\mathrm{C}=\mathrm{CH}_{2}+\dot{\mathrm{C}} \mathrm{H}_{3}
\end{aligned}
$$


and with the initiation of the chains through the reaction (7) of the generated allene with isobutylene:

$$
\mathrm{CH}_{2}=\mathrm{C}=\mathrm{CH}_{2}+\mathrm{CH}_{2}=\mathrm{C}\left(\mathrm{CH}_{3}\right)_{2} \rightarrow \mathrm{CH}_{2}=\mathrm{CH}-\dot{\mathrm{C}} \mathrm{H}_{2}+\mathrm{CH}_{2}=\mathrm{C}\left(\mathrm{CH}_{3}\right) \dot{\mathrm{C}} \mathrm{H}_{2}
$$

due to a very low endothermicity of the latter reaction.

Calculation of thermal effect of the reaction (7), according to the thermodynamic data [7], gives a value of $75 \mathrm{~kJ} / \mathrm{mol}$ only. At this, the rate of chain initiation is equal to $k \cdot\left[C_{3} H_{4}\right] \cdot\left[\right.$ iso $\left.-C_{4} H_{8}\right]$, where $k$ is the reaction rate constant. At the isobutene concentration of $10^{18}$ molecules $\cdot \mathrm{cm}^{-3}$ and allene concentration of $10^{16}$ molecules $\cdot \mathrm{cm}^{-3}$, one can assume that the rate of this reaction is $10^{-11} \cdot e^{\frac{-75000}{R T}} \cdot 10^{16} \cdot 10^{18}$ (where $10^{-11}$ is the specific number of molecular collisions at the steric coefficient presumably equal to 0.1 $\mathrm{cm}^{3} \cdot$ molecule $\mathrm{e}^{-1} \cdot \mathrm{s}^{-1}$ (with taking into account the available experimental data for similar reactions, [9]) and at a temperature of $800 \mathrm{~K}$ is equal to $10^{18}$ molecule $\cdot \mathrm{cm}^{-3} \cdot \mathrm{s}^{-1}$.

Initiation due to the decomposition of isobutylene by the reaction (8):

$$
\mathrm{CH}_{2}=\mathrm{C}\left(\mathrm{CH}_{3}\right)_{2} \rightarrow \mathrm{CH}_{2}=\mathrm{C}\left(\mathrm{CH}_{3}\right) \dot{\mathrm{C}} \mathrm{H}_{2}+\dot{H}
$$

requires an energy expenditure of $318 \mathrm{~kJ} / \mathrm{mol}$ (according to the data of [7]).

The rate of this reaction is equal to $10^{15} e^{-\frac{318000}{R \cdot 800}} 10^{18}=10^{12}$ molecule $\cdot \mathrm{cm}^{-3} \cdot \mathrm{s}^{-1}$, where $10^{15} \mathrm{~s}^{-1}$ is the frequency of molecular vibrations on the reactive bond, i.e. the initiation of chains on allene proceeds $10^{6}$ fold faster than the monomolecular decomposition of isobutylene.

\section{EXPERIMENTAL STUDY OF INITIATION OF THERMAL DECOMPOSITION OF HYDROCARBONS BY ALLENE}

\subsection{Research methods}

Pyrolysis was carried out in quartz tubes of 2-5.5 $\mathrm{mm}$ in diameter, placed in a tube furnace with a known temperature field, under dilution with helium. The temperature was measured by platinum-platinum-rhodium thermocouples with an accuracy of $\pm 2^{\circ} \mathrm{C}$. The results of the pyrolysis were determined chromatographically.

Effect of allene on the kinetics of thermal decomposition of n-hexene- 1 was studied at 823-893 $\mathrm{K}$ at the concentration of n-hexene-1 in helium of 2-5 mol \%.

Effect of allene on the thermal decomposition of $n$-hexane was studied in a temperature range of $903-963 \mathrm{~K}$ at the concentration of n-hexane in helium of $2-6 \mathrm{~mol} \%$ with the allene addition, relative to $\mathrm{n}$-hexane, of $0.475 \pm 0.025 \mathrm{~mol} \%$. To study effect of allene on the kinetics of thermal decomposition of n-hexane, in a number of experiments the allene concentration, relative to $\mathrm{n}$-hexane, varied within $0.45 \div 13.8 \mathrm{~mol} \%$.

Effect of allene on the pyrolysis of gasoline fractions of oil was studied on the pyrolysis of the $70-140^{\circ} \mathrm{C}$ fraction of the mixture of Tyumen oils. Pyrolysis was carried out under dilution with helium at a molar ratio of helium: gasoline of 1:3.

\subsection{Initiation of thermal decomposition of n-hexene-1}

Results of investigation of effect of allene on thermal decomposition of n-hexene-1 are shown in Fig. 1. As can be seen from the data obtained, with the allene addition decomposition of 

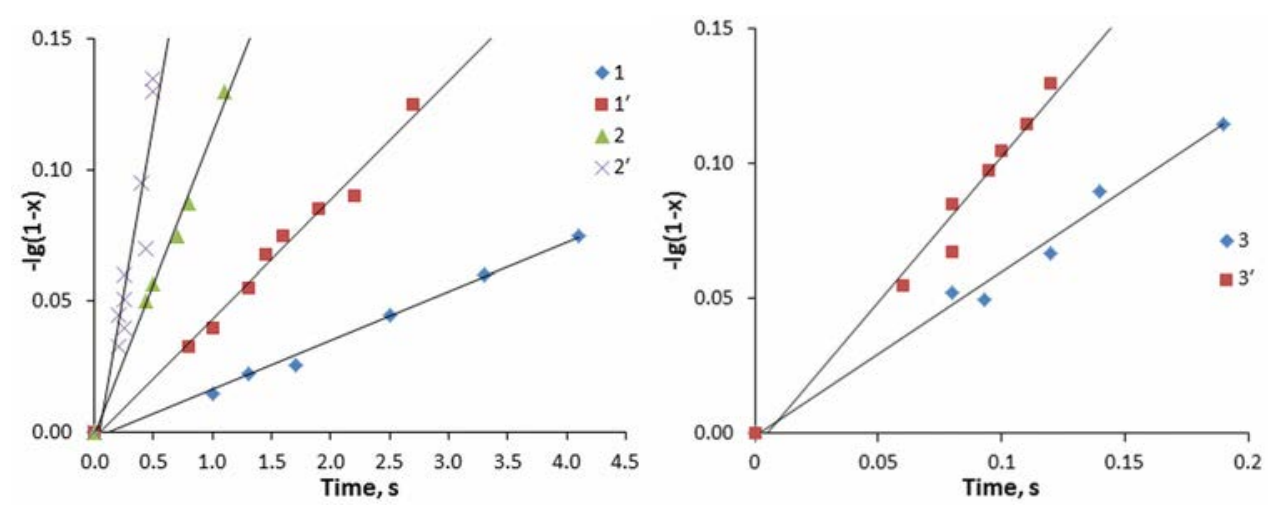

Figure 1: Effect of the allene addition on the kinetics of decomposition of n-hexene- 1 at different temperatures: $1,1^{\prime}-823 \mathrm{~K}, 2,2^{\prime}-873 \mathrm{~K}, 3,3^{\prime}-923 \mathrm{~K} ; 1,2,3$ - n-hexene$1,1^{\prime}, 2^{\prime}, 3^{\prime}-\mathrm{n}$-hexene-1 with the allene addition of $0.5 \mathrm{~mol} \%$.

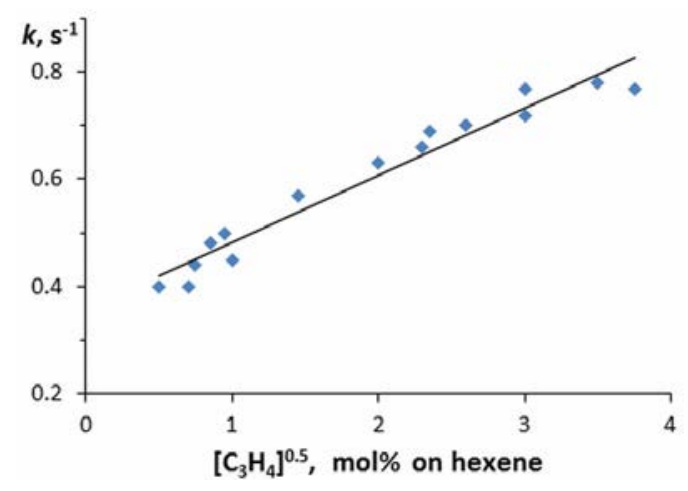

Figure 2: Dependence of the effective constant of the thermal decomposition rate of nhexene- 1 on the concentration of allene at $873 \mathrm{~K}$.

n-hexene-1 is significantly accelerated. The specific rate of decomposition of n-hexene- 1 in the presence of $0.5 \mathrm{~mol} \%$ of allene increases 2.6 fold at $823 \mathrm{~K}$ and 1.7 fold at $923 \mathrm{~K}$.

Fig. 2 presents the results of investigation of effect of allene concentration on the kinetics of the pyrolysis of n-hexene- 1 at $873 \mathrm{~K}$. The composition of the pyrolysis products is virtually the same as without allene (Table 1).

\subsection{Initiation of thermal decomposition of n-hexane}

Fig. 3 shows results of investigation of effect of allene on the kinetics of thermal decomposition of $n$-hexane. With allene addition, the rate of decomposition increases significantly; at $903 \mathrm{~K}$, the specific rate of decomposition of $\mathrm{n}$-hexane increases by a factor of 7.5 and at $963 \mathrm{~K}$ - by a factor of 3.3 .

Fig. 4 shows the results of investigation of effect of allene concentration on the kinetics of the pyrolysis of n-hexane at $903 \mathrm{~K}$. Selectivity of formation of the decomposition 
products in the pyrolysis process of n-hexane in pure form and in the presence of $0.5 \mathrm{~mol} \%$ of allene are the same (Table 2).

Table 1: Composition of the pyrolysis products of hexene-1 in a pure form and in the presence of $0.5 \mathrm{~mol} \%$ of allene at $873 \mathrm{~K}$.

\begin{tabular}{|l|l|l|}
\hline Indicators & n-hexene-1 & $\begin{array}{l}\text { n-hexene- } 1+0.5 \mathrm{~mol} \% \text { of } \\
\mathrm{C}_{3} \mathrm{H}_{4}\end{array}$ \\
\hline $\begin{array}{l}\text { Initial concentration of } \mathrm{C}_{6} \mathrm{H}_{12} \text { in } \\
\text { helium, mol\% }\end{array}$ & $14.0 \div 15.0$ & $2.0 \div 5.0$ \\
\hline Reaction time, $\mathrm{s}$ & $0.3-1.0$ & \\
\hline Depth of decomposition, \% & $8.2-18.8$ & $0.115-0.55$ \\
\hline Number of tests & 10 & $7.0-24.2$ \\
\hline Yield, mol/100 mol of & & \\
decomposed $\mathrm{C}_{6} \mathrm{H}_{12}:$ & & \\
$\mathrm{CH}_{4}$ & $26.6 \pm 0.7$ & $24.9 \pm 0.1$ \\
$\mathrm{C}_{2} \mathrm{H}_{6}$ & $9.7 \pm 0.1$ & $9.4 \pm 0.2$ \\
$\mathrm{C}_{2} \mathrm{H}_{4}$ & $66.3 \pm 0.8$ & $65.2 \pm 0.8$ \\
$\mathrm{C}_{3} \mathrm{H}_{6}$ & $67.1 \pm 0.5$ & $69.4 \pm 0.3$ \\
$\mathrm{C}_{4} \mathrm{H}_{8}-1$ & $16.9 \pm 0.3$ & $16.7 \pm 0.3$ \\
$\mathrm{C}_{4} \mathrm{H}_{6}-1,3$ & $23.9 \pm 0.4$ & $24.2 \pm 0.7$ \\
$\mathrm{C}_{5} \mathrm{H}_{10}-1$ & $10.8 \pm 0.3$ & $9.5 \pm 0.3$ \\
\hline
\end{tabular}

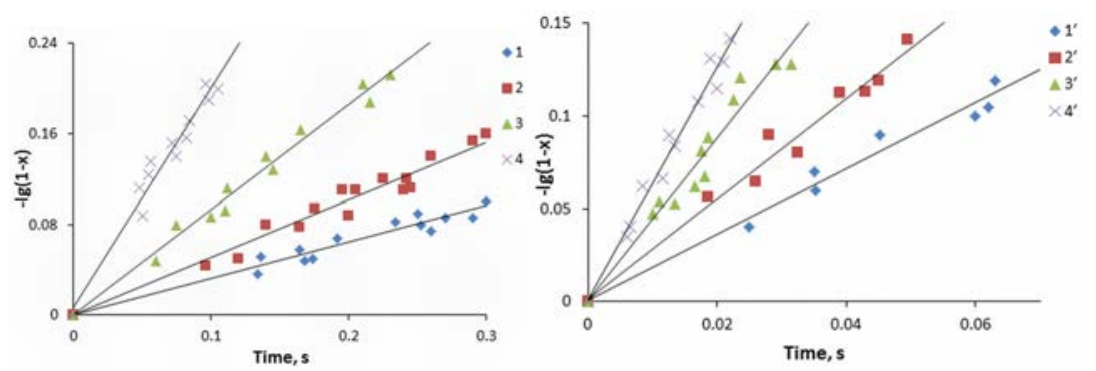

Figure 3: Effect of allene addition on the kinetics of decomposition of n-hexane at different temperatures: 1, 1'-903 K, 2, 2'-923 K, 3, 3'-943 K; 4, 4 '- $963 \mathrm{~K}$; 1,2,3,4-nhexane, 1 ', 2', 3 ', 4'-n-hexane with the allene addition of $0.5 \mathrm{~mol} \%$.

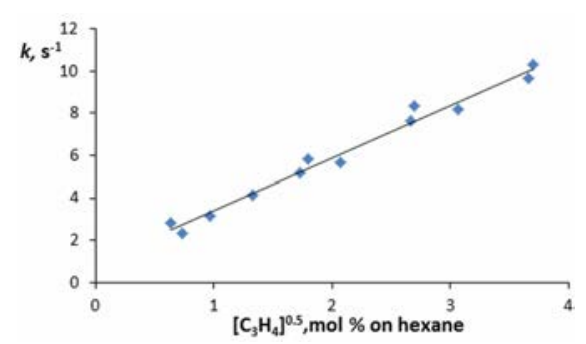

Figure 4: Dependence of the effective constant of the thermal decomposition rate of nhexane on the concentration of allene at $903 \mathrm{~K}$. 
Table 2: Ratio of the yields of n-hexane decomposition products to the yield of ethylene, $\mathrm{mol} / \mathrm{mol}$ at $903 \mathrm{~K}$ in the pyrolysis of pure hexane and hexane with the allene addition of $0.5 \mathrm{~mol} \%$.

\begin{tabular}{|l|l|l|}
\hline Indicators & Hexane & Hexane+allene \\
\hline Conversion of hexane, $\%$ & $3.60 \div 12.99$ & $5.60 \div 11.30$ \\
\hline $\mathrm{CH}_{4}$ & $0.54 \pm 0.02$ & $0.55 \pm 0.01$ \\
\hline $\mathrm{C}_{2} \mathrm{H}_{5}$ & $0.09 \pm 0.02$ & $0.09 \pm 0.02$ \\
\hline $\mathrm{C}_{3} \mathrm{H}_{6}$ & $0.48 \pm 0.03$ & $0.52 \pm 0.02$ \\
\hline $\mathrm{C}_{4} \mathrm{H}_{8}-1$ & $0.29 \pm 0.02$ & $0.30 \pm 0.01$ \\
\hline $\mathrm{C}_{5} \mathrm{H}_{10}-1$ & $0.09 \pm 0.01$ & $0.10 \pm 0.01$ \\
\hline Number of tests & 4 & 5 \\
\hline
\end{tabular}

\subsection{Initiation of the pyrolysis of liquid raw materials by allene}

Fig. 5 shows kinetic curves of methane, ethane, ethylene, and propylene formation in the pyrolysis of gasoline at $1073 \mathrm{~K}$, with the allene addition in amount of $0.3 \mathrm{wt} \%$ at the same temperature, and with the allene addition in amount of $0.5 \mathrm{wt} . \%$ at $1053 \mathrm{~K}$. Allene significantly accelerates the pyrolysis. At $1073 \mathrm{~K}$, the maximum yield of ethylene during the pyrolysis of the gasoline fraction is reached within the time of pyrolysis of 0.6-0.7 s, and the maximum yield of propylene is reached within the time of 0.4-0.5 s. In the presence of allene, the maximum yield of ethylene at this temperature is reached within the time of $0.17-0.30 \mathrm{~s}$, and for propylene the time is less than $0.17 \mathrm{~s}$.

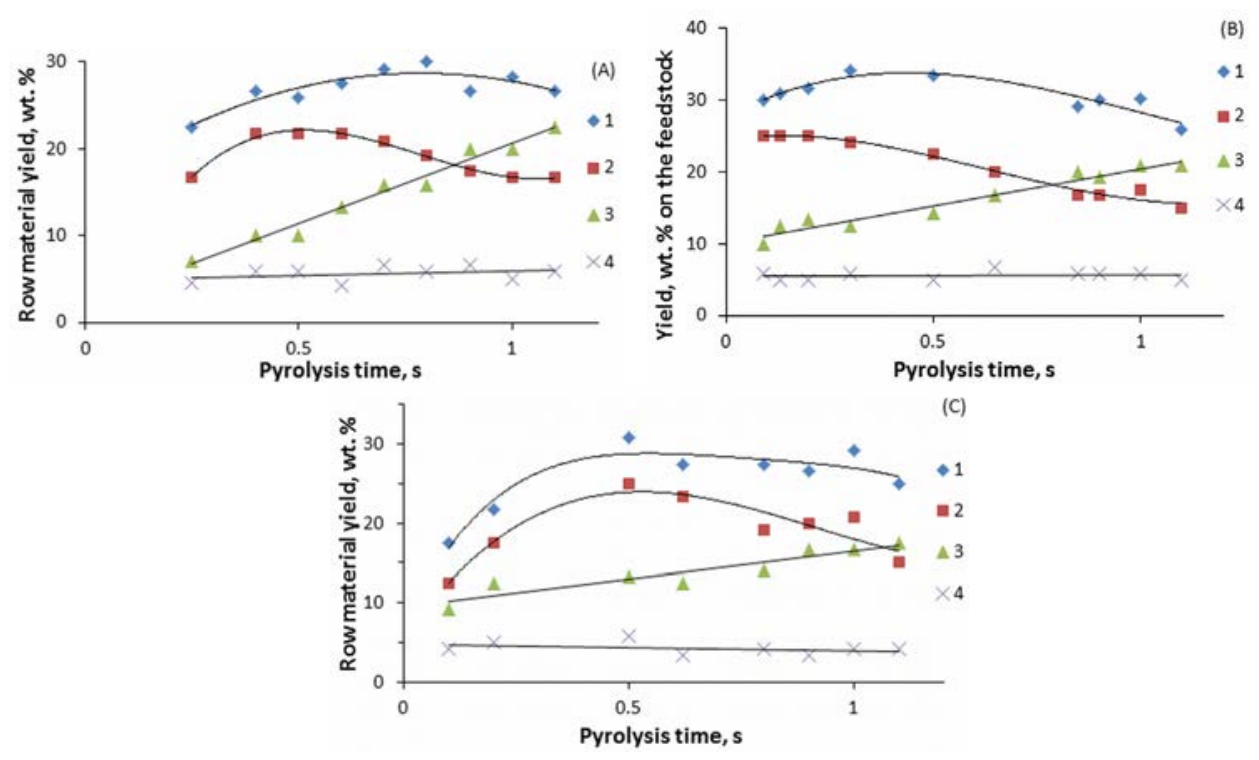

Figure 5: Yields of the pyrolysis products of the gasoline fraction $70-140^{\circ} \mathrm{C}$ : ethylene (1), propylene (2), methane (3), ethane (4). (A) - without allene at $1073 \mathrm{~K}$; (B) - with the allene addition of 0.3 wt. $\%$ at $1073 \mathrm{~K}$; (C) - with the allene addition of 0.5 wt. $\%$ at $1053 \mathrm{~K}$. 
In the pyrolysis process with allene, the yield of ethylene and propylene at the optimum pyrolysis time significantly increases. In the conventional pyrolysis (at $1073 \mathrm{~K}$ ), the maximum yield of ethylene was $28.5 \mathrm{wt}$ \%, in the pyrolysis with allene it was $32.5 \mathrm{wt}$. \%; the yield of propylene at the maximum yield of ethylene was 21 and $23 \mathrm{wt} . \%$, respectively; and the maximum yield of propylene was 22.5 and $24 \mathrm{wt} \%$, respectively. The yields of ethane and methane in the conventional pyrolysis and those with the allene addition can be assumed to be the same. With allene addition, the pyrolysis process, when the temperature is lowered to $1053 \mathrm{~K}$, gives approximately the same results as at $1073 \mathrm{~K}$ without allene, the yields of ethylene and propylene are the same or by $0.5-1 \mathrm{wt} \%$ higher.

\section{CONCLUSIONS}

It was theoretically justified that initiation of chains during the reaction of allene with olefins can be much faster than other reactions of initiation. The accelerating effect of allene is associated with initiation of chains as a result of bimolecular formation of radicals in the disproportionation of allene with hydrocarbon.

It was established that the allene addition into the pyrolysis feedstock increases the yield of ethylene under the same process mode and boosts energy efficiency of the ethylene production process.

In the industrial pyrolysis of $\mathrm{C}_{3}-\mathrm{C}_{4}$ gases and gasoline, allene is generated at the highest temperatures at the end of the pyrolysis coil as a result of the reactions of successive removal of hydrogen atoms from propylene $\mathrm{C}_{3} \mathrm{H}_{6} \rightarrow \dot{C}_{3} H_{5}+\dot{H} \rightarrow \mathrm{C}_{3} H_{4}+\dot{H}$. In this case, allene does not have a significant effect on the results of the process. If allene is recycled in the feedstock to the area with relatively low temperatures, the process selectivity for ethylene increases.

The obtained results provide an opportunity to improve the pyrolysis of the petroleum feedstock by carrying out the process in the presence of the effective initiator - allene.

\section{ACKNOWLEDGEMENT}

This research was supported by Act 211 Government of the Russian Federation, contract № 02. A03.21.0006.

\section{REFERENCES}

[1] Global Ethylene Market Outlook: Low Cost Feedstocks Fuel the Next Wave of Investments in North America and China. Inaugural Ethylene Forum Online, Available from: http://media.corporate-ir.net/media_files/IROL/11/110877/ 05_Global_Ethylene_Market_Outlook_Eramo.pdf

[2] Wang, X.Q., Xie, C.G., Li, Z.T. \& Z Z hu, G.Q., Catalytic processes for light olefin production (Chapter 5). Practical Advances in Petroleum Processing, eds. C.S. Hsu \& P.R. Robinson, Springer Science - Business Media, Inc.: New York, 1, pp. 149$168,2006$.

[3] Benson, S.W., Some Recent Developments in the Gas-Phase Pyrolysis of Hydrocarbons (Chapter 1). Advances in Chemistry Series, 97. Edited by Spillone, L.J. \& Leftin, H.P., American Chemical Society: New York, 119, 1970.

[4] Aqsha, A., Tijani, M.M. \& Mahinpey, N., Catalytic pyrolysis of straw biomasses (wheat, flax, oat and barley straw) and the comparison of their product yields. WIT Transactions on Ecology and The Environment, 190(2), 1007-1015, 2014.

[5] Lewandowski, W.M., Radziemska, E., Ryms, M. \& Ostrowski, P., Modern methods of thermochemical biomass conversion into gas, liquid and solid fuels. Ecological Chemistry and Engineering, 18(1), 39-47, 2011. 
[6] Grigiante, M., Ischia, M., Baratieri, M., Maschio, R.D. \& Ragazzi, M., Pyrolysis analysis and solid residue stabilization of polymers, waste tyres, spruce sawdust and sewage sludge. Waste and Biomass Valorization, 1(4), 381-393, 2010.

[7] Vedeneyev, V.I., Gurvich, L.V., Kondratyev, V.N., Medvedev, V.A. \& Frankevich Y.L., Bond energies, ionization potentials, and electron affinities, St. Martin's Press, Inc.: New York, 1966.

[8] Zhorov, Yu.M., Thermodynamics of chemical processes: petrochemical synthesis, processing of petroleum, coal, and natural gas, Mir Publishers: Moscow, 1987.

[9] Kondratiev, V.N., Rate constants of gas phase reactions, National Bureau of Standards: Washington, 1972. 